\title{
Filamin-A is required to mediate SST2 effects in pancreatic neuroendocrine tumours
}

\author{
Eleonora Vitali ${ }^{1}$, Valeria Cambiaghi', Alessandro Zerbi ${ }^{2}$, Carlo Carnaghi ${ }^{3}$, \\ Piergiuseppe Colombo ${ }^{4}$, Erika Peverelli ${ }^{5}$, Anna Spada ${ }^{5}$, Giovanna Mantovani ${ }^{5}$ \\ and Andrea G Lania6,7
}

'Laboratory of Cellular and Molecular Endocrinology, IRCCS Clinical and Research Institute Humanitas, Via Manzoni 56, 20089 Rozzano, Milan, Italy

${ }^{2}$ Pancreas Surgery Unit, IRCCS Humanitas Research Hospital, Via Manzoni 56, 20089 Rozzano, Milan, Italy ${ }^{3}$ Medical Oncology and Hematology Unit, Cancer Center, IRCCS Humanitas Research Hospital, Via Manzoni 56, 20089 Rozzano, Milan, Italy

${ }^{4}$ Pathology Unit, IRCCS Humanitas Research Hospital, Via Manzoni 56, 20089 Rozzano, Milan, Italy

${ }^{5}$ Fondazione IRCCS Ospedale Maggiore Policlinico, Endocrinology and Diabetology Unit, Department of Clinical Sciences and Community Health, University of Milan, Via F Sforza 35, 20100 Milan, Italy ${ }^{6}$ Department of Biomedical Sciences, Humanitas University, Rozzano, Milan, Italy

${ }^{7}$ Endocrinology Unit, Humanitas Research Hospital, Via Manzoni 56, 20089 Rozzano, Milan, Italy

Correspondence should be addressed to A G Lania Email andrea.lania@humanitas.it

\begin{abstract}
Somatostatin receptor type 2 (SST2) is the main pharmacological target of somatostatin (SS) analogues widely used in patients with pancreatic neuroendocrine tumours (P-NETs), this treatment being ineffective in a subset of patients. Since it has been demonstrated that Filamin A (FLNA) is involved in mediating GPCR expression, membrane anchoring and signalling, we investigated the role of this cytoskeleton protein in SST2 expression and signalling, angiogenesis, cell adhesion and cell migration in human P-NETs and in QGP1 cell line. We demonstrated that FLNA silencing was not able to affect SST2 expression in P-NET cells in basal conditions. Conversely, a significant reduction in SST2 expression $(-43 \pm 21 \%$, $P<0.05$ vs untreated cells) was observed in FLNA silenced QGP1 cells after long term SST2 activation with BIM23120. Moreover, the inhibitory effect of BIM23120 on cyclin D1 expression ( $-46 \pm 18 \%, P<0.05$ vs untreated cells), P-ERK1/2 levels $(-42 \pm 14 \% ; P<0.05$ vs untreated cells), cAMP accumulation ( $-24 \pm 3 \%, P<0.05$ vs untreated cells), VEGF expression $(-31 \pm 5 \%, P<0.01$ vs untreated cells) and in vitro release $(-40 \pm 24 \%, P<0.05$ vs untreated cells) was completely lost after FLNA silencing. Interestingly, BIM23120 promoted cell adhesion ( $+86 \pm 45 \%, P<0.05$ vs untreated cells) and inhibited cell migration $(-24 \pm 2 \%$, $P<0.00001$ vs untreated cells) in P-NETs cells and these effects were abolished in FLNA silenced cells. In conclusion, we demonstrated that FLNA plays a crucial role in SST2 expression and signalling, angiogenesis, cell adhesion and cell migration in P-NETs and in QGP1 cell line, suggesting a possible role of FLNA in determining the different responsiveness to SS analogues observed in P-NET patients.
\end{abstract}

\section{Key Words}

- neuroendocrine tumours

- somatostatin

- filamin A

- somatostatin receptor type 2 


\section{Introduction}

Somatostatin (SS) is a ubiquitous peptide that physiologically inhibits hormone secretion from neuroendocrine cells. In particular, SS inhibits pituitary GH and TSH secretion and insulin, glucagon, and secretin secretion at gastro-entero-pancreatic level (Van Op den Bosch et al. 2009, Reubi \& Schonbrunn 2013). These effects are mediated by five receptor subtypes (SST1-5) belonging to the G protein coupled receptors superfamily (GPCR) that differ in tissue distribution, affinity to ligands and mechanisms of action and regulation (Patel 1998, Lahlou et al. 2004). As demonstrated in cells transfected with different receptor subtypes and confirmed by the clinical use of selective agonists, SST2 and to lesser extent SST5 and SST3 appear to mediate most of the antisecretive and antiproliferative effects of SS (Reubi \& Schonbrunn 2013).

Most neuroendocrine tumours (NETs) express SST2 and 5 that are targets for the long-acting SS analogues (Papotti et al. 2002, Reubi \& Schonbrunn 2013, Theodoropoulou \& Stalla 2013). Although in vivo and in vitro evidences support the antiproliferative action of SS in neuroendocrine cells, NETs show a variable biological response to SS analogues. In particular, octreotide LAR and lanreotide SR (with a preferential binding affinity for SST2) have been demonstrated to control both the symptoms and hormone secretion in 50-60\% of patients with functioning NET. Moreover, SS analogues have been found to stabilise tumour mass in 30-50\% of patients, with a significant reduction in tumour mass being observed in a minority of them (Rinke et al. 2009, Öberg 2012, Caplin et al 2014), but the mechanisms involved in the resistance in non-responders patients being still unknown.

Several studies demonstrated that GPCRs expression and signalling are mediated by different cytoskeleton proteins, including filamin A (FLNA; Stossel et al. 2001, Huang et al. 2006). FLNA is a ubiquitous actin binding protein, involved in cell morphology and motility regulation, acts as a molecular scaffold for several proteins, including transmembrane proteins and signalling molecules. In addition, the relevance of FLNA in pituitary tumour responsiveness to pharmacological treatment has been demonstrated in PRL-secreting pituitary tumours, where FLNA plays a key role in dopamine receptor type 2 signalling and cell surface expression (Peverelli et al. 2012). Recently, FLNA/SST2 interaction has been found to play a critical role for SST2 stabilization and cell survival in human pancreatic tumour cells (BON) and in melanoma cell line (Najib et al. 2012) as well as in tumourous pituitary GH-secreting cells (Peverelli et al. 2014).
Moreover, the involvement of cytoskeletal actinbinding proteins in angiogenesis has been suggested as a target for anti-neovascular cancer therapy in vitro. In fact, a positive relationship between FLNA and vascular endothelial growth factor (VEGF) was found in patients with lung cancer (Uramoto et al. 2010), suggesting that FLNA is implicated in angiogenesis through links with VEGF. Interestingly, it has been demonstrated that VEGF pathway is overexpressed in neuroendocrine tumours (Öberg et al. 2013), this pathway being inhibited by somatostatin analogues (Villaume et al. 2010).

In addition, FLNA allows the cross-linking of actin filaments into a dynamic three dimensional structure and mediates the anchoring of several transmembrane proteins to the cortical actin. These FLNA functions are crucial for cell adhesion to extracellular matrix, cell locomotion and migration (Xu et al. 2010).

Aim of the present study was to investigate the role of FLNA in the regulation of SST2 stabilization, signalling, angiogenesis and cell motility in pancreatic neuroendocrine tumour cells.

\section{Materials and methods}

\section{Immunohistochemistry}

Immunohistochemistry experiments were performed on sections from 29 P-NETs retrieved from the archives of Pathology Unit of IRCCS Humanitas Research Hospital, Rozzano, Milan, Italy. After dewaxing in Bioclear and rehydrating in ethanol, sections were pre-treated in a water bath set to $98^{\circ} \mathrm{C}$ in $0.01 \mathrm{M}$ citrate buffer for $25 \mathrm{~min}$. Mouse Monoclonal FLNA antibody (MAB1678, Millipore, Billerica, Massachusetts, USA, 1:600 dilution) and rabbit monoclonal SST2 antibody (ab134152, UMB-1; Abcam, Cambridge, UK; 1:200 dilution) were used, and antigenantibody detection was performed with the MACH1 universal polymer detection kit (Biocare Medical, Concord, CA, USA). FLNA and SST2 immunoreactivities were graded according to the previously described immunohistochemical score (Peverelli et al. 2012) and analysed by an observer not connected with the project, evaluating at least 100 cells/section.

\section{Pancreatic neuroendocrine tumour cell cultures}

The study was approved by the local ethics committee. Informed consent was obtained from all subjects involved in the study. Human neuroendocrine cells were obtained

Published by Bioscientifica Ltd. 
from 11 P-NETs that were enzymatically dissociated in DMEM containing $2 \mathrm{mg} / \mathrm{ml}$ collagenase (Sigma-Aldrich Corporate Headquarters) at $37^{\circ} \mathrm{C}$ for $2 \mathrm{~h}$. Dispersed cells were cultured in DMEM supplemented with 10\% fetal bovine serum, $2 \mathrm{mM}$ glutamine and antibiotics. Human pancreatic endocrine QGP-1 cell line (carcinoembryonic antigen (CEA)-producing human pancreatic islet cell carcinoma, JCRB0183, Japanese Homo Sapiens) was grown in RPMI 1640 medium supplemented with 10\% FBS, $2 \mathrm{mM}$ glutamine and antibiotics. QGP1 cell line was cultured at $37^{\circ} \mathrm{C}$ in $5 \% \mathrm{CO}_{2}$ atmosphere.

\section{FLNA silencing in pancreatic neuroendocrine cells}

In order to obtain the best efficiency of FLNA silencing three different human FLNA silencer select pre-designed siRNAs (Ambion, Austin, TX, USA) were tested. Preliminary experiments to determine the optimal concentration of siRNAs and the kinetics of silencing of FLNA were performed. A negative control siRNA (C- siRNA), a non-targeting sequence without significant homology to the sequence of human, mouse or rat transcripts, was used in each experiment. Western blotting was performed in each experiment to control the FLNA expression level after silencing. FLNA gene silencing was performed in P-NET and QGP1 cells using species-specific human FLNA predesigned siRNA (sense 5'-3', CCAACAAGCCCAACAAGUUTT and antisense AACUUGUUGGGCUUGUUGGTG) and Lipofectamine 2000 transfection reagent (Invitrogen) according to the manufacturer's instruction. Briefly, 400000 cells were seeded into six-wells plates. Lipofectamine $2000(5 \mu \mathrm{l})$ was diluted in Opti-MEM (Invitrogen) and FLNA siRNA, used at a concentration $30 \mathrm{nM}$, was also diluted in Opti-MEM, then added to diluted Lipofectamine 2000 Reagent (1:1 ratio) and incubated for $5 \mathrm{~min}$ at room temperature. Subsequently, QGP1 cells were incubated with the mixture for $72 \mathrm{~h}$.

\section{Western immunoblots of SST2, cyclin D1, pERK1/2 and VEGF proteins}

QGP1 cells were treated with FLNA siRNA or C-siRNA and incubated at $37^{\circ} \mathrm{C}$ withBIM23120 $10 \mathrm{nM}$ for $72 \mathrm{~h}$ to analyse SST2 and VEGF expression, $6 \mathrm{~h}$ for cyclin D1 and $10 \mathrm{~min}$ for pERK1/2. Cells were then lysed in lysis buffer in the presence of protease inhibitors. Proteins were separated on SDS/PAGE and transferred to a nitrocellulose filter. Antibodies raised against epitopes specific for SST2 (Santa Cruz; 1:200, sc365502, monoclonal antibody) and FLNA (Abnova, 1:1000, monoclonal antibody, \#H00002316-M01) and then anti-mouse HRP- linked antibodies (Cell Signalling 1:2000, \#7076) were used to detect the total levels of the SST2 and FLNA proteins. Densitometric data were normalized to vinculin antibody (\#4650, Cell Signalling, 1:1000).

The 1:10000 dilution of anti-cyclin D1, (monoclonal antibody, 04-1151, EMD Millipore) and anti-rabbit HRPlinked antibodies (Cell Signalling, 1:2000, \#7074) were used to detect cyclin D1 expression levels. Monoclonal anti-GAPDH (AM4300, Ambion, 1:4000) was used as housekeeping, developed using an anti-mouse secondary antibody.

To detect phosphorylated ERK1/2, 1:2000 dilution of antiphospho-p42/44 monoclonal antibody (\#4370, Cell Signalling) and an anti-rabbit antibody were used. The presence of total ERK1/2 was analysed by stripping and

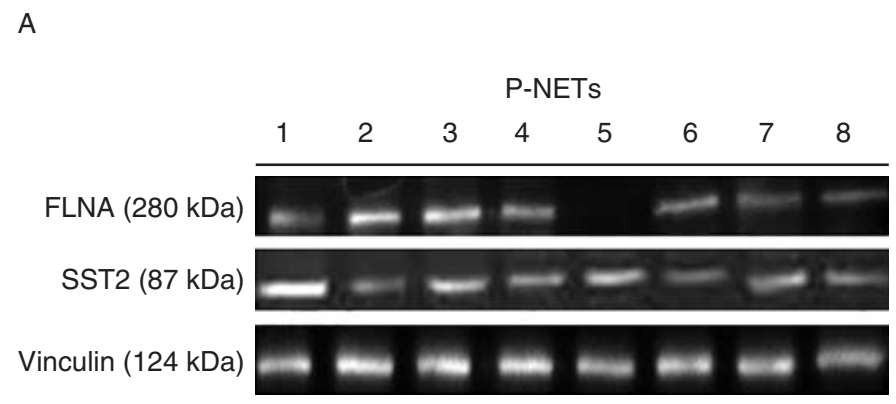

A
B

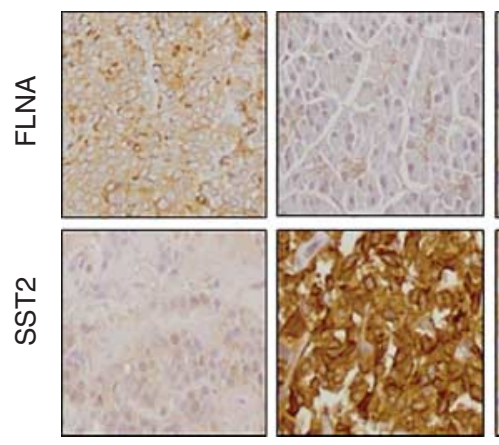

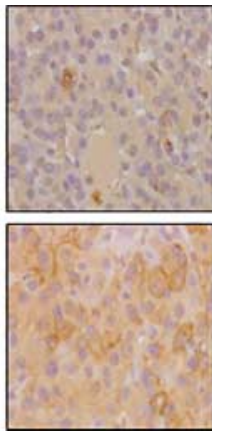

Figure 1

FLNA expression in P-NETs. (A) Immunoblots of FLNA and SST2 performed on eight different neuroendocrine tumour samples. FLNA was expressed at variable levels in different samples, without correlation with SST2 expression. (B) Representative pictures of immunohistochemistry for FLNA and SST2 in different GEP-NETs ( $20 \times$ magnification). FLNA and SST2 pictures in the same column correspond to the same tumour. Confirming western-blot data, no correlation between SST2 and FLNA expression have been found.

Published by Bioscientifica Ltd 
reprobing with anti-total p42/44 monoclonal antibody (1:1000; Cell Signalling, \#4695) and developed using an anti-rabbit secondary antibody. The 1:1000 dilution of VEGF (Abcam, ab46154, polyclonal antibody) and an anti-rabbit antibody were used. GAPDH was used as housekeeping.

After enzyme-linked chemiluminescence membrane incubation (Immobilon Western Chemiluminescent HRP Substrate, Millipore), chemiluminescence was detected using the ChemiDoc-MP Imaging System (Bio-Rad Laboratories, Inc.) and analysed using the image analysis program NIH ImageJ. Experiments were repeated three times.

\section{CAMP assay}

To quantify the inhibition of forskolin-induced cAMP accumulation, QGP1 cells transfected with FLNA siRNA or negative control siRNA were preincubated with $0.5 \mathrm{mM}$ 3-isobutyl-1-methylxantine (IBMX) for $30 \mathrm{~min}$, and subsequently with $1 \mathrm{mM}$ forskolin with or without BIM23120
$10 \mathrm{nM}$ for $30 \mathrm{~min}$ at $37^{\circ} \mathrm{C}$. Intracellular cAMP was measured by enzymatic immunoassay (Promega).

\section{VEGF secretion study}

To analyse VEGF secretion, QGP1 cells were distributed in 24-well tissue culture plates and incubated with FLNA siRNA or negative control siRNA for $72 \mathrm{~h}$. After incubation, cells were treated with or without BIM23120 $10 \mathrm{nM}$ in serum free RPMI-1640 medium for $72 \mathrm{~h}$ at $37^{\circ} \mathrm{C}$. Collected supernatants were used to measured VEGF concentration with ELISA kit (Invitrogen), according to manufacturer instructions. The absorbance was measured in a microplate reader at $450 \mathrm{~nm}$ and the sample values of VEGF were read off the standard procedure.

\section{Cell adhesion assay}

To analyse the role of FLNA in mediating SST2 effects on cell adhesion in QGP1 and P-NETs primary cultures, cells

Table 1 Pathological findings and FLNA/SST2 score immunoreactivity of P-NETs included in the IHC study

\begin{tabular}{|c|c|c|c|c|c|}
\hline Case number & Grade & Ki-67\% & Mitoses X 10 HPF & IHC score SST2 & IHC score FLNA \\
\hline 9 & G1 & $<1$ & $<2$ & 9 & 3 \\
\hline 10 & $\mathrm{G} 2$ & 2 & 2 & 6 & 3 \\
\hline 11 & G1 & 1 & $<2$ & 0 & 3 \\
\hline 12 & G1 & 1 & $<2$ & 9 & 3 \\
\hline 13 & G2 & 4 & 2 & 9 & 0 \\
\hline 14 & G1 & 2 & 1 & 9 & 3 \\
\hline 15 & G1 & 1 & $<1$ & 6 & 0 \\
\hline 16 & G2 & 3 & 1 & 9 & 6 \\
\hline 17 & $\mathrm{G} 2$ & 10 & 2 & 6 & 6 \\
\hline 18 & G1 & 1 & $<1$ & 9 & 3 \\
\hline 19 & G2 & 4 & 2 & 9 & 3 \\
\hline 20 & G1 & 1 & $<1$ & 6 & 3 \\
\hline 21 & G1 & 2 & $<2$ & 9 & 3 \\
\hline 22 & G1 & 1 & $<1$ & 3 & 3 \\
\hline 23 & G2 & 3 & 2 & 9 & 3 \\
\hline 24 & G1 & 1 & $<1$ & 9 & 6 \\
\hline 25 & G1 & 2 & 1 & 6 & 6 \\
\hline 26 & $\mathrm{G} 2$ & 5 & 5 & 9 & 2 \\
\hline 27 & $\mathrm{G} 2$ & 3 & 1 & 9 & 1 \\
\hline 28 & G1 & 1 & $<2$ & 9 & 2 \\
\hline 29 & G1 & $1-2$ & $<2$ & 9 & 0 \\
\hline 30 & G1 & 1 & 1 & 9 & 3 \\
\hline 31 & $\mathrm{G} 2$ & 7 & 2 & 9 & 1 \\
\hline 32 & G1 & $2-3$ & $<2$ & 9 & 0 \\
\hline 33 & G1 & $<1$ & $<1$ & 9 & 0 \\
\hline 34 & $\mathrm{G} 2$ & 4 & 2 & 9 & 0 \\
\hline 35 & $\mathrm{G} 2$ & 30 & $>2$ & 6 & 6 \\
\hline 36 & G1 & 10 & 2 & 9 & 0 \\
\hline 37 & G3 & $>70$ & 45 & 2 & 4 \\
\hline
\end{tabular}

FLNA and SST2 immunoreactivities were graded taking into account both the percentage of positive cells $(0-30 \%=1,31-60 \%=2,61-100 \%=3)$ and the staining intensity $(0=$ absence of immunoreactivity; $1=$ weak; $2=$ medium intensity; and $3=$ strong reactivity) and evaluating at least 100 cells per section. G1= low tumour grade, G2=intermediate tumour grade, G3=high-tumour grade. HPF=high power fields. Ki-67\%= marker to quantify the proliferative rate. 
with or without FLNA siRNA were plated onto a collagen type IV-coated 48-well plate and incubated with or without BIM23120 $10 \mathrm{nM}$ in serum-free medium for $90 \mathrm{~min}$ at $37^{\circ} \mathrm{C}$, as by manufacturer's protocol (Cell Biolabs, Inc., San Diego, CA, USA). Briefly, nonadherent cells were removed by gently washing plates 4-5 times with PBS, adherent cells were lysed and subsequently detected with CyQuant GR Dye (Cell Biolabs, Inc.). Finally, each extracted sample was quantified by measuring fluorescence at $480 \mathrm{~nm} / 520 \mathrm{~nm}$. The experiment was performed four times in quadruplicate.

\section{Cell migration assay}

To analyse the role of FLNA in mediating SST2 effects on cell migration, QGP1 cells silenced or not were plated in polycarbonate membrane plate (Cell Biolabs, Inc.) with or without BIM23120 $10 \mathrm{nM}$ in serum-free RPMI and placed into the feeder tray, containing chemoattractant solution, according to the instruction of the manufacturer. After $24 \mathrm{~h}$ of incubation at $37^{\circ} \mathrm{C}$, migratory cells were first dissociated from the membrane, then stained and quantified after extraction using a fluorometric plate reader.

\section{Statistical analysis}

The results were expressed as mean \pm s.D. A paired twotailed Student's $t$-test was used to detect the significance between two series of data. $P<0.05$ was accepted as statistically significant.

\section{Results}

\section{FLNA is not involved in SST2 expression in P-NETs}

We first evaluated FLNA and SST2 expression in P-NETs by both western blotting $(n=8)$ and immunohistochemistry $(n=29)$. FLNA was expressed at variable levels in different samples (Fig. 1A and B), without significant correlation with SST2 expression. In addition, as shown in Table 1, we did not find any correlation between clinical phenotype of different P-NETs and immunohistochemistry score of both proteins.

\section{FLNA is not required for SST2 expression in basal condition but it reduces SST2 expression after long-term agonist stimulation in QGP1 cells}

To overcome the limitations due to the low availability of fresh neuroendocrine tumour samples and the low number of cells obtained, we used human pancreatic neuroendocrine cell line QGP1, endogenously expressing SST2 and FLNA, as a model for P-NET.

We analysed the effects of FLNA knockdown by siRNA against FLNA in QGP1 cells. Three days after transfection, in the absence of additional stimuli, western blot analysis showed a significant decrease of FLNA levels with respect to negative control, without affecting SST2 protein expression (Fig. 2A), these data suggesting that in neuroendocrine tumours FLNA is not required for SST2 expression in basal conditions. Thus, we decided to study the possible involvement of FLNA on SST2 downregulation after agonist stimulation. To test the impact of FLNA on SST2 stability, QGP1 cells were transfected with C-siRNA and FLNA siRNA and then incubated with or without BIM23120 $10 \mathrm{nM}$. As shown in Fig. 2B, long-term BIM23120 treatment $(72 \mathrm{~h})$ induced a significant reduction in SST2 expression in cells silenced for FLNA ( $-43 \pm 21 \%, P<0.05$ vs untreated cells). Conversely,

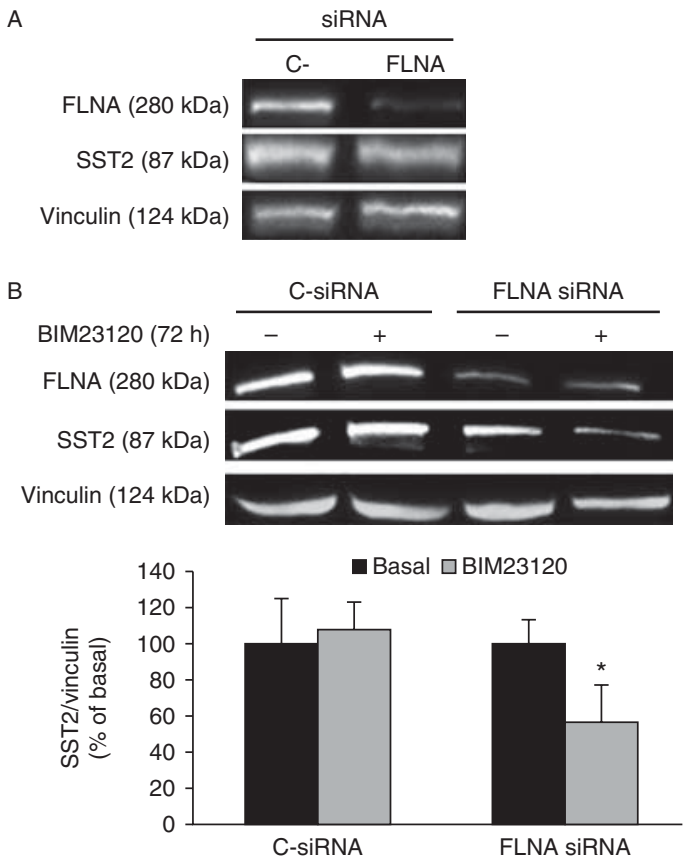

Figure 2

(A) SST2 expression does not depend on FLNA levels. Representative immunoblot of FLNA and SST2 in QGP1 cells transiently transfected with negative control (C-siRNA) or FLNA siRNA for $72 \mathrm{~h}$. FLNA siRNA treated cells showed a strong decrease in FLNA protein expression that was not associated with SST2 expression. (B) Representative immunoblots of SST2 and FLNA showing that the silencing of FLNA reduced SST2 expression after long-term agonist stimulation (10 nM BIM23120 for $72 \mathrm{~h}$ ) in QGP1 cells. In the absence of stimulation, basal SST2 expression was comparable to FLNA-silenced cells. Data represent mean \pm s.D. of three independent experiments. ${ }^{*} P<0.05$ vs basal.

Published by Bioscientifica Ltd 
in control cells BIM23120 treatment did not affect SST2 protein levels as evaluated by western blot.

\section{FLNA is required for SST2 signalling in QGP1 cells}

To investigate the role of FLNA in SST2 signalling, we evaluated the somatostatin analogue inhibition of forskolin-induced intracellular cAMP accumulation, that reflects the reduction in adenylyl cyclase activity in the presence of phosphodiesterase inhibitors. BIM23120 at $10 \mathrm{nM}$ inhibited forskolin-stimulated cAMP accumulation in cells transfected with negative control siRNA $(-24 \pm 3 \%$, $P<0.05$ vs basal) (Fig. 3A), while this effect was abrogated in FLNA silenced cells.

To study the impact of FLNA in SST2-mediated inhibition of cell proliferation, we analysed the effects of SST2 activation on extracellular signal-regulated kinase (ERK1/2) phosphorylation, that mediates the anti-mitotic effect of SS analogue. BIM23120 significant decreased ERK1/2 phosphorylation in control cells $(-42 \pm 14 \%$ in negative control transfected cells, $P<0.05$ vs untreated cells) and this reduction was totally abolished in silenced cells (Fig. 3B).

In addition, we further studied the antiproliferative effects of SST2 by evaluating the reduction of cyclin D1 levels induced by the specific SST2 agonist BIM23120 in
FLNA-silenced QGP1 cells (Fig. 3C). As shown, the reduction of cyclin D1 levels observed in control cells after $6 \mathrm{~h}$ of BIM23120 incubation $(-46 \pm 18 \%, P<0.05$ vs untreated cells) was completely abolished after FLNA silencing.

\section{FLNA is involved in SST2-mediated angiogenesis inhibition}

To study the role of FLNA in SST2-mediated angiogenesis inhibition, we analysed the effects of SST2 on VEGF protein expression and secretion. As expected BIM23120 incubation induced a decrease in both VEGF expression $(-31 \pm 5 \%$ in negative control transfected cells, $P<0.01$ vs untreated cells) and in vitro release $(-40 \pm 24 \%$ in negative control transfected cells, $P<0.05$ vs untreated cells), these effects being completely abolished by FLNA silencing (Fig. 4A and B).

\section{FLNA is involved in SST2-mediated effects on cell adhesion and migration}

To analyse the involvement of FLNA in SST2-mediated cell adhesion, a pivotal event in the cancer development and progression, we examined the effects of SST2 on cell adhesion by incubation of BIM23120 in FLNA silenced P-NETs primary cultured cells. Interestingly, BIM23120

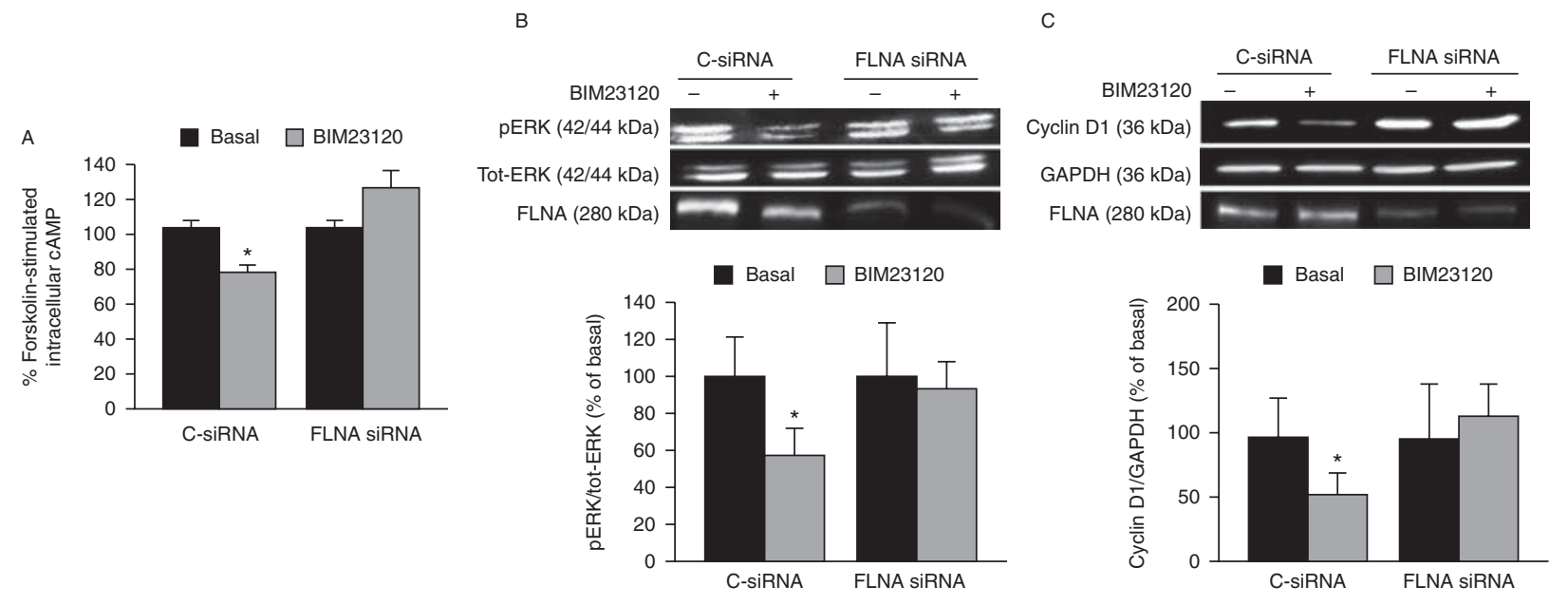

\section{Figure 3}

Effects of FLNA silencing on SST2 signalling in QGP1 cells. (A) Effect of FLNA silencing on SST2-mediated adenylyl cyclase inhibition. In cells transfected with C-siRNA, the SST2 selective agonist BIM23120 inhibited forskolinstimulated CAMP accumulation. Cells transfected with FLNA siRNA abolished CAMP inhibition with respect to control cells. Experiments were repeated at least three times and each determination was done in quadruplicate. Values represent mean \pm s.D. ${ }^{*} P<0.05$ vs corresponding basal. (B) Representative immunoblot of ERK1/2 phosphorylation demonstrating that SST2-mediated inhibition of ERK1/2 by BIM23120 (10 nM for $10 \mathrm{~min}$ ) was present in C-siRNA and abolished in FLNA siRNA transfected QGP1 cells. The graph shows the quantification of phospho-ERK1/2 normalized to total ERK1/2 (mean \pm s.D. from three independent experiments). Values represent mean \pm s.D. ${ }^{*} P<0.05$ vs corresponding basal. (C) Effect of BIM23120 treatment (10 nM) on cyclin D1 expression on cells transfected for $72 \mathrm{~h}$ with $\mathrm{C}$ - siRNA or FLNA siRNA. In C- siRNA BIM23120 caused a significant inhibition of cyclin D1 levels, whereas no effect on cyclin D1 expression was mediated by SST2 in FLNA siRNA. Experimentswere repeated at least three times. Values represent mean \pm s.D. ${ }^{*} P<0.05$ vs corresponding basal. 

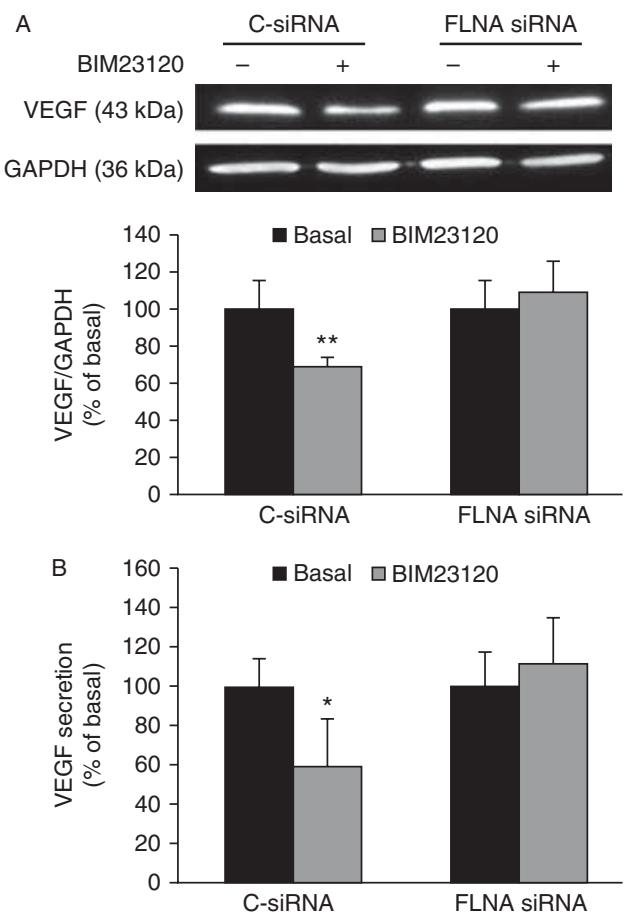

Figure 4

Effects of FLNA silencing on SST2-mediated angiogenesis inhibition in QGP1 cells. (A) Representative immunoblot of VEGF demonstrating that SST2 inhibitory effect on VEGF mediated by BIM23120 ( $10 \mathrm{nM}$ for $72 \mathrm{~h}$ ) was present in C-siRNA and abolished in FLNA siRNA transfected QGP1 cells. The graph shows the quantification of VEGF normalized to GAPDH (mean \pm s.D. from four independent experiments). $* * P<0.01$ vs corresponding basal. (B) Effects of FLNA silencing on SST2-mediated VEGF secretion inhibition. In cells transfected with C-siRNA, the SST2 selective agonist BIM23120 (10 nM) inhibited VEGF secretion after $72 \mathrm{~h}$ incubation. Cells transfected with FLNA siRNA abolished VEGF secretion inhibition with respect to control cells. Experiments were repeated at least four times and each determination was done in quadruplicate. Values represent mean \pm s.D. ${ }^{*} P<0.05$ vs corresponding basal. promoted cell adhesion in control cells $(+46 \pm 2 \%$, $P<0.01$ vs basal) and this effect was completely abolished in cells lacking FLNA (Fig. 5A).

To confirm the results obtained with P-NET cells, SST2-mediated stimulation of cell adhesion was tested in QGP1 cells transfected for $72 \mathrm{~h}$ with FLNA siRNA or negative control siRNA. As expected, QGP1 cells expressing FLNA showed an increase of cell adhesion by BIM23120 ( $+86 \pm 45 \%$ at $10 \mathrm{nM}, P<0.05$ vs basal), that was abrogated in FLNA silenced cells (Fig. 5B).

We then analysed the regulation of cell migration mediated by SST2. Exposure of QGP1 cells transfected with the negative control siRNA to SST2 selective agonist BIM23120 caused a reduction of cell migration at $10 \mathrm{nM}$ $(-24 \pm 2 \%, P<0.00001$ vs basal), this inhibitory effect being completely lost in FLNA silenced cells (Fig. 5C).

\section{Discussion}

In the present study we demonstrated that FLNA, a widely expressed cytoskeleton protein, has a crucial role in SST2 stabilization at the membrane level, but it is not involved in SST2 expression. Contrary to what observed in PRLsecreting adenoma, in which low D2R expression is associated with low FLNA levels (Peverelli et al. 2012), and in agreement with what demonstrated in GH-secreting adenoma (Peverelli et al. 2014), no correspondence between FLNA and SST2 expression was found in P-NETs. Moreover, no significant correlations were found between FLNA expression and either clinical presentation or pathological findings (i.e. grading), this finding being in contrast with other cancer types. In fact, it has been
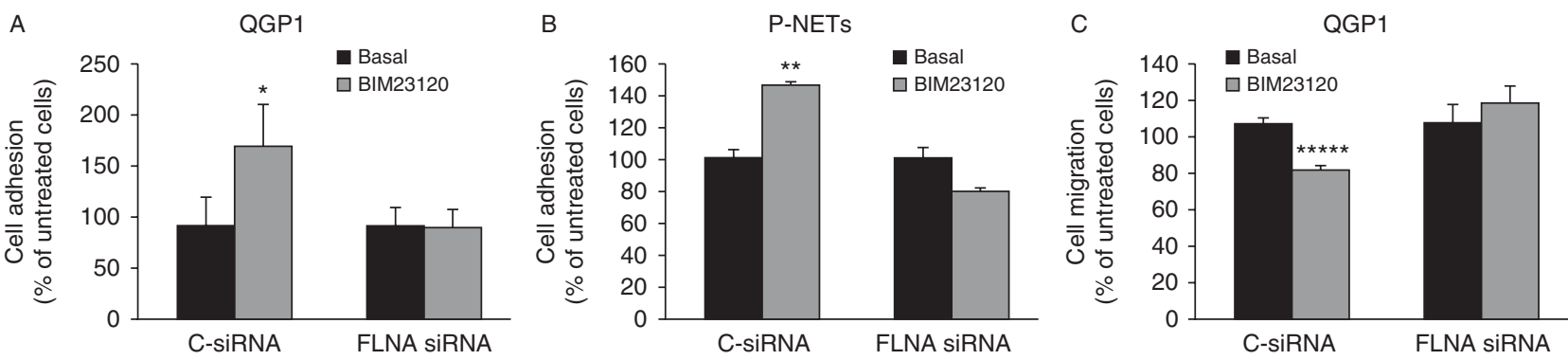

\section{Figure 5}

Effects of FLNA silencing on cell motility. ( $A$ and B) QGP1 cells and three different P-NETs transfected with C-siRNA or FLNA siRNA were incubated with or without BIM23120 $10 \mathrm{nM}$ for $90 \mathrm{~min}$ at $37^{\circ} \mathrm{C}$. Experimentscarried out in QGP1 cells were repeated at least four times and each determination was done in quadruplicate. The graphs showed the quantification of adherent cells. Values represent mean \pm s.D. ${ }^{\star} P<0.05$ vs corresponding basal, ${ }^{*} P<0.01$ vs corresponding basal. (C) QGP1 cells FLNA silenced or transfected with C-siRNA were incubated for $24 \mathrm{~h}$ with or without BIM23120 at $10 \mathrm{nM}$. Migratory cells were quantified by fluorometric plate reader. The experiment was performed in triplicate four times. Values represent mean \pm s.D. $* * * * * P<0.00001$ vs corresponding basal. 
demonstrated that FLNA is overexpressed in multiple types of cancer, including prostate, breast, lung cancer, hemangiomas, colon cancer, melanoma, neuroblastoma, squamous cell carcinoma, hepatic cholangiocarcinoma, this overexpression possibly correlating with cancer aggressiveness (Savoy \& Ghosh 2013, Yue et al. 2013). To confirm the result obtained by immunohistochemistry and western blot in a series of human P-NETs, we performed further experiments on QGP1 cells, an appropriate cellular model that expresses endogenously FLNA and SST2. We showed that FLNA silencing did not result in receptor levels modifications in QGP1 cells, thus suggesting that SST2 expression is not dependent on FLNA levels. Although our data demonstrated that FLNA is not required for SST2 basal expression, we then investigated the possible role of FLNA on SST2 stabilization after prolonged agonist stimulation in QGP1 cells. Our results showed that in QGP1 cells FLNA knockdown reduced SST2 stability after long-term agonist incubation, whereas BIM23120 did not affect SST2 protein levels in control cells. Our observation is in agreement with recent data carried out on GH-secreting adenoma (Peverelli et al. 2014) and on FLNA deficient melanoma cell lines M2 (Najib et al. 2012). Although, further studies will be needed to fully understand how FLNA regulates SST2 stability, several evidences indicate that FLNA plays a crucial role in trafficking and stabilizing several GPCRs on plasma membrane (Liu et al. 1997, Seck et al. 2003, Thelin et al. 2007). In this respect, it is worth noting that FLNA directly interacts with $\beta$-arrestins (Scott et al. 2006), suggesting that a complex receptor-FLNA-arrestin may be possibly involved in SST2 down-regulation processes.

In neuroendocrine tumours, the modification of receptor stability resulting from FLNA silencing has a profound impact on SST2 signalling. In fact, in the absence of FLNA the selective SST2 agonist was unable to trigger the most relevant biological responses mediated by SS analogues (i.e. inhibition of cell proliferation). In particular, our data demonstrated that FLNA knockdown resulted in the loss of the ability of SST2 agonist to reduce intracellular cAMP accumulation, ERK 1/2 phosphorylation and cyclin D1 levels.

Moreover, we demonstrated that FLNA is required for mediating SST2 inhibitory effect on angiogenesis that represents a crucial cellular event for cancer progression. In particular, it has been demonstrated that FLNA physically interacts with HIF-1 $\alpha$ (Zhenga et al. 2014), that regulates angiogenesis through upregulation of vascular endothelial growth factor (VEGF) (Uramoto et al. 2010, Berardi et al. 2011, Semenza 2012). Whereas
VEGF-driven angiogenesis may play an important role in endocrine tumourigenesis and tumour progression (Hanahan et al. 1996) and several in vitro studies suggested that SS analogues display potent antiangiogenic properties (Woltering et al. 1991, Barrie et al. 1993, Danesi \& Del Tacca 1996, Kumar et al. 2004), we showed that SST2 agonist reduced VEGF protein levels and release, but this inhibitory effect was totally abolished in the absence of FLNA.

In addition, considering that pancreatic neuroendocrine tumours are characterized by widely disseminated metastatic disease at diagnosis, we focused on two key events in tumour development, such as cell adhesion and migration. In particular, to the best of our knowledge, our study is the first to characterize SST2 selective agonist effect on cell adhesion and migration in neuroendocrine tumours. According to the few studies on the role of somatostatin analogues on cell motility that have been carried out on other cellular system (Talme et al. 2001, Tang et al. 2010), we demonstrated that somatostatin analogue promoted cell adhesion and inhibited cell migration. To study the implication of FLNA on SST2 regulation of cancer development, we modulated FLNA expression, providing evidence that FLNA silencing abolished stimulatory and inhibitory effect of SST2 agonist on cell adhesion and cell migration respectively. These data suggested that FLNA is crucial for regulation of SST2-mediated cell mobility in pancreatic neuroendocrine tumour cells.

In conclusion, these results provide new evidence for a role of cytoskeleton in the control of neuroendocrine tumour progression triggered by SST2. In particular, our data demonstrated that FLNA is required to maintain SST2 stability after agonist stimulation, to mediate SST2 signal transduction and to regulate angiogenesis and cell motility.

\section{Declaration of interest}

The authors declare that there is no conflict of interest that could be perceived as prejudicing the impartiality of the research reported.

\section{Funding}

This work has been supported by AIRC grant (IG-13051) and by an unrestricted grant by Novartis and Ipsen.

\section{Acknowledgements}

We thank Dr F Pasqualini and Dr S Mantero for their contribution to the immunohistochemical studies and Doctor Culler for providing us with BIM23102. We also thank Fondazione Umberto Veronesi (post-doctoral fellowship E.V.).

Published by Bioscientifica Ltd. 


\section{References}

Barrie R, Woltering EA, Hajarizadeh H, Mueller C, Ure T \& Fletcher WS 1993 Inhibition of angiogenesis by somatostatin and somatostatin-like compounds is structurally depend. Journal of Surgical Research $\mathbf{5 5}$ 446-450. (doi:10.1006/jsre.1993.1167)

Berardi S, Caivano A, Ria R, Nico B, Savino R, Terracciano R, De Tullio G, Ferrucci A, De Luisi A, Moschetta M et al. 2011 Four proteins governing overangiogenic endothelial cell phenotype in patients with multiple myeloma are plausible therapeutic targets. Oncogene 31 2258-2269. (doi:10.1038/onc.2011.412)

Caplin ME, Pavel M, Ćwikła JB, Phan AT, Raderer M, Sedláčková E, Cadiot G, Wolin EM, Capdevila J, Wall L et al. 2014 Lanreotide in metastatic enteropancreatic neuroendocrine tumours. New England Journal of Medicine 37 1224-1233. (doi:10.1056/NEJMoa1316158)

Danesi R \& Del Tacca M 1996 The effects of the somatostatin analog octreotide on angiogenesis in vitro. Metabolism 45 49-50. (doi:10.1016/ S0026-0495(96)90080-3)

Hanahan D, Christofori G, Naik P \& Arbeit J 1996 Transgenic mouse models of tumour angiogenesis: the angiogenic switch, its molecular controls, and prospects for preclinical therapeutic models. European Journal of Cancer 32 2386-2393. (doi:10.1016/S0959-8049(96)00401-7)

Huang C, Wu Z, Hujer KM \& Miller RT 2006 Silencing of filamin A gene expression inhibits $\mathrm{Ca}^{2+}$-sensing receptor signalling. FEBS Letter $\mathbf{5 8 0}$ 1795-1800. (doi:10.1016/j.febslet.2006.02.035)

Kumar M, Liu ZR, Thapa L \& Qin RY 2004 Anti-angiogenic effects of somatostatin receptor subtype 2 on human pancreatic cancer xenografts. Carcinogenesis 25 2075-2081. (doi:10.1093/carcin/bgh216)

Lahlou H, Guillermet J, Hortala M, Vernejoul F, Pyronnet S, Bousquet C \& Susini C 2004 Molecular signalling of somatostatin receptors. Annals of the New York Academy of Sciences 1014 121-131. (doi:10.1196/annals. 1294.012)

Liu G, Thomas L, Warren RA, Enns CA, Cunningham CC, Hartwig JH, Hartwig JH \& Thomas G 1997 Cytoskeletal protein ABP-280 directs the intracellular trafficking of furin and modulates proprotein processing in the endocytic pathway. Journal of Cell Biology 139 1719-1733. (doi:10.1083/jcb.139.7.1719)

Najib S, Saint-Laurent N, Estève JP, Schulz S, Boutet-Robinet E, Fourmy D, Lättig J, Mollereau C, Pyronnet S, Susini C et al. 2012 A switch of G protein-coupled receptor binding preference from phosphoinositide 3-kinase (PI3K)-p85 to filamin A negatively controls the PI3K pathway. Molecular \& Cellular Proteomics 32 1004-1016. (doi:10.1128/ mcb.06252-11)

Öberg K 2012 Biotherapies for GEP-NETs. Best Practice \& Research. Clinical Gastroenterology 26 833-841. (doi:10.1016/j.bpg.2013.01.001)

Öberg K, Casanovas O, Castaño JP, Chung D, Delle Fave G, Denèfle P, Harris P, Khan MS, Kulke MH \& Scarpa A 2013 Molecular pathogenesis of neuroendocrine tumours: implications for current and future therapeutic approaches. Clinical Cancer Research 19 2842-2849. (doi:10.1158/1078-0432.ccr-12-3458)

Papotti M, Bongiovanni M, Volante M, Allìa E, Landolfi S, Helboe L, Schindler M, Cole SL \& Bussolati G 2002 Expression of somatostatin receptor types 1-5 in 81 cases of gastrointestinal and pancreatic endocrine tumours. A correlative immunohistochemical and reversetranscriptase polymerase chain reaction analysis. Virchows Archiv $\mathbf{4 4 0}$ 461-475. (doi:10.1007/s00428-002-0609-x)

Patel YC 1998 Somatostatin and its receptor family. Frontiers in Neuroendocrinology 20 157-198. (doi:10.1006/frne.1999.0183)

Peverelli E, Mantovani G, Vitali E, Elli FM, Olgiati L, Ferrero S, Laws ER, Della Mina P, Villa A, Beck-Peccoz P et al. 2012 Filamin-A is essential for dopamine $\mathrm{d} 2$ receptor expression and signalling in tumourous lactotrophs. Journal of Clinical Endocrinology and Metabolism 97 967-977. (doi:10.1210/jc.2011-2902)

Peverelli E, Giardino E, Treppiedi D, Vitali E, Cambiaghi V, Locatelli M, Lasio GB, Spada A, Lania AG \& Mantovani G 2014 Filamin A (FLNA) plays an essential role in somatostatin receptor 2 (SST2) signalling and stabilization after agonist stimulation in human and rat somatotroph tumour cells. Endocrinology 155 2932-2941. (doi:10.1210/en.20141063)

Reubi JC \& Schonbrunn A 2013 Illuminating somatostatin analog action at neuroendocrine tumour receptors. Trends in Pharmacological Sciences $\mathbf{3 4}$ 676-688. (doi:10.1016/j.tips.2013.10.001)

Rinke A, Müller HH, Schade-Brittinger C, Klose KJ, Barth P, Wied M, Mayer C, Aminossadati B, Pape UF \& Bläker M 2009 Placebo-controlled, double-blind, prospective, randomized study on the effect of octreotide LAR in the control of tumour growth in patients with metastatic neuroendocrine midgut tumours: a report from the PROMID Study Group. Journal of Clinical Oncology 27 4656-4663. (doi:10.1200/JCO. 2009.22.8510)

Savoy RM \& Ghosh PM 2013 The dual role of filamin A in cancer: can't live with (too much of) it, can't live without it. Endocrine-Related Cancer 20 341-356. (doi:10.1530/ERC-13-0364)

Scott MG, Pierotti V, Storez H, Lindberg E, Thuret A, Muntaner O, Labbé-Jullié C, Pitcher JA \& Marullo S 2006 Cooperative regulation of extracellular signal-regulated kinase activation and cell shape change by filamin A and $\beta$-arrestins. Molecular and Cellular Biology 26 3432-3445. (doi:10.1128/МСВ.26.9.3432-3445.2006)

Seck T, Baron R \& Horne WC 2003 Binding of filamin to the C-terminal tail of the calcitonin receptor controls recycling. Journal of Biological Chemistry 278 10408-10416. (doi:10.1074/jbc.M209655200)

Semenza GL 2012 Hypoxia-inducible factors: Mediators of cancer progression and targets for cancer therapy. Trends in Pharmacological Sciences 33 207-214. (doi:10.1016/j.tips.2012.01.005)

Stossel TP, Condeelis J, Cooley L, Hartwig JH, Noegel A, Schleicher M \& Shapiro SS 2001 Filamins as integrators of cell mechanics and signalling. Nature Reviews. Molecular Cell Biology 2 138-145. (doi:10.1038/35052082)

Talme T, Ivanoff J, Hägglund M, Van Neerven RJ, Ivanoff A \& Sundqvist KG 2001 Somatostatin receptor (SSTR) expression and function in normal and leukaemic T-cells. Evidence for selective effects on adhesion to extracellular matrix components via SSTR2 and/or 3. Clinical and Experimental Immunology 125 71-79. (doi:10.1046/j.1365-2249.2001. 01577.x)

Tang X, Takekoshi S, Itoh J, Umemura S, Shoji S, Terachi T \& Osamura RY 2010 Somatostatin analogue inhibits the mobility of prostate carcinoma cells: a new therapeutic method for advanced prostate carcinoma. International Journal of Oncology 37 1077-1083. (doi:10.3892/ijo_00000759)

Thelin WR, Chen Y, Gentzsch M, Kreda SM, Sallee JL, Scarlett CO, Borchers CH, Jacobson K, Stutts MJ \& Milgram SL 2007 Direct interaction with filamins modulates the stability and plasma membrane expression of CFTR. Journal of Clinical Investigation 117 364-374. (doi:10.1172/JCI30376)

Theodoropoulou M \& Stalla GK 2013 Somatostatin receptors: from signalling to clinical practice. Frontiers in Neuroendocrinology 34 228-252. (doi:10.1016/i.yfrne.2013.07.005)

Uramoto H, Akyürek LM \& Hanagiri T 2010 A positive relationship between filamin and VEGF in patients with lung cancer. Anticancer Research 30 3939-3944. (doi:10.1002/cncr.24193)

Van Op den Bosch J, Adriaensen D, Van Nassauw L \& Timmermans JP 2009 The role(s) of somatostatin, structurally related peptides and somatostatin receptors in the gastrointestinal tract: a review. Regulatory Peptides 156 1-8. (doi:10.1016/j.regpep.2009.04.003)

Villaume K, Blanc M, Gouysse G, Walter T, Couderc C, Nejjari M, Vercherat C, Cordier-Bussat M, Roche C \& Scoazec JY 2010 VEGF secretion by neuroendocrine tumour cells is inhibited by octreotide and by inhibitors of the PI3K/AKT/mTOR pathway. Neuroendocrinology 91 268-278. (doi:10.1159/000289569)

Woltering EA, Barrie R, O'Dorisio TM, Arce D, Ure T, Cramer A, Holmes D, Robertson J \& Fassler J 1991 Somatostatin analogs inhibit angiogenesis 
in the chick chorioallantoic membrane. Journal of Surgical Research 50 245-251. (doi:10.1016/0022-4804(91)90186-P)

Xu Y, Bismar TA, Su J, Xu B, Kristiansen G, Varga Z, Teng L, Ingber DE, Mammoto A \& Kumar R 2010 Filamin A regulates focaladhesiondisassembly and suppresses breast cancercell migrationand invasion. Journal of Experimental Medicine 207 2421-2437. (doi:10.1084/jem. 20100433)
Yue J, Huhn S \& Shen Z 2013 Complex roles of filamin-A mediated cytoskeleton network in cancer progression. Cell \& bioscience 37 . (doi:10.1186/2045-3701-3-7)

Zhenga X, Zhou AX, Rouhi P, Uramoto H, Borén J, Cao Y, Pereira T, Akyürek LM \& Poellinger L 2014 Hypoxia-induced and calpaindependent cleavage of filamin A regulates the hypoxic response. PNAS 111 2560-2565. (doi:10.1073/pnas.1320815111)

Received in final form 24 December 2015

Accepted 4 January 2016

Made available online as an Accepted Preprint

5 January 2016
Published by Bioscientifica Ltd. 